\title{
Bulgaria: regulating pornography in the new digital realities
}

\section{Elza Ibroscheva}

Department of Mass Communications, Southern Illinois University Edwardsville, Edwardsville, United States of America, eibrosc@siue.edu

Published on 16 Dec 2016 | DOI: 10.14763/2016.4.439

\begin{abstract}
This study offers an overview of the legal and cultural discourse surrounding pornography in the newest European Union member state, Bulgaria. With the collapse of communism, pornography became one of the fastest and most sought after media imports, a staple of street culture and late night entertainment. The study offers a critical analysis of the legal, cultural, and political challenges to monitoring and regulating the traditional and digital means for distributing and consuming pornography, revealing the complex frameworks, transnational institutional mechanisms and regional responses involved in defining and regulating pornography in the new digital realities.
\end{abstract}

Keywords: Media law, Pornography, Bulgaria

\section{Article information}

\author{
Received: 01 Jun 2016 Reviewed: 14 Sep 2016 Published: 16 Dec 2016 \\ Licence: Creative Commons Attribution 3.0 Germany \\ Competing interests: The author has declared that no competing interests exist that have influenced \\ the text.
}

URL: http://policyreview.info/articles/analysis/bulgaria-regulating-pornography-new-digital-realities

In March 2013, the European Parliament contemplated a proposed bill intended to criminalise pornography in response to increasing pressures from various constituencies to eliminate gender and sexual stereotypes. The bill was a reaction to a report prepared by the Committee on Women's Rights and Gender Equality, proposing a number of measures to improve gender equality within EU members states, which among other things, called for "a ban on all forms of pornography in the media and on the advertising of sex tourism" (2012/2116(INI), Article 17).

In response to the report, the European Parliament voted 368-159 in favour of passing it, with 98 abstaining. However, the controversial "porn ban" was rejected. Many internet freedom advocates, including Christian Engström, a Member of the European Parliament (MEP) and deputy leader of the Swedish Pirate Party, noted that while the goals of the Committee were "of course very laudable", as always, "the devil is in the detail" (Engström, 2013, n.p.). The defeat of this bill demonstrated that enforcing legal measures concerning online pornography is an 
enormous trial. While the introduction of the bill was hailed as a pioneering effort on the part of the EU to establish and enforce unprecedented measures of monitoring online pornography and the growing culture of exploitation of women's sexualities in the media, its controversial porn ban was rejected for its potential to stifle free speech. This paper offers an overview of the legal and cultural discourse surrounding the regulation of pornography in the newest European member state, Bulgaria. As a former socialist state, Bulgaria treated the topic of pornography as an ideological issue, a problem of the morally corrupt West, and therefore, minimised its relevance to social and legal discourse. With the collapse of communism, however, pornography became one of the fastest and most sought after media imports, which quickly turned into a staple of street culture and late night entertainment. While widely accessible, pornography is not defined or regulated by media law. In fact, Bulgaria only recently began modifying the few existing criminal legal measures, partly because of the increasing pressure from the European Union (Zankova, 2013). By looking at the historic and cultural context of pornography law in Bulgaria, this paper offers a critical analysis of the legal, cultural, and political challenges to monitoring and regulating the traditional and digital means for distributing and consuming pornography thus, using it as a case study to explore the complex transnational institutional mechanisms and regional responses involved in policy matters related to pornography, especially in the new digital realities of the world and the Eastern European region, in specific.

As an attempt to study policy in a larger transnational context, this study offers a new direction in policy studies because as Burgelman (1997) has argued, "there is a need to look into the tension between the national, the European, and the global levels in communication policy" (p. 141). In academia, the most common approaches to studying pornography come from a feminist critique of the representation of female sexuality. In this area, three authors, namely, Dworkin ([1979] 1999\}, Kendrick ([1987] 1996), and Kipnis (1996) represent the different ways in which the term pornography is used and applied, in theory, allowing for productive difference that enables a multi-dimensional analysis of sexual texts. Among these established critical perspectives, Kendrick's view of the role of regulations as a means of defining what sexual content is considered pornographic is theoretically closest to the study at hand. However, the study takes on a different approach from Kendrick's since the current study concerns itself with online pornography, also acknowledging the relevance of internet governance literature, which has influenced much of the debate concerning what is in fact the best way to ensure the proper, equitable and legally sound operation of a global network of information that knows no borders nor has discernable physical attributes. Internet governance functions carry significant public interest implications and how these functions are diffusely distributed among new institutional forms, the private sector, and more traditional forms of governance. Among those, matters of regulation and control have been used to both compare and distinguish the offline world from the online one in order to create a corresponding framework of global policies and regulations. which remains a sizeable challenge. This challenge is further complicated by the unprecedented speed of technology innovation and the failure and often virtual impossibility of national and international regulatory bodies to respond to those changes at the same rate.

Specifically, this paper addresses the following research questions: how has the cultural and legal discourse on pornography regulation evolved over time? How has this discursive evolution impacted the current effort to regulate online pornography in Bulgaria? Finally, how do the current challenges in regulating online pornography in Bulgaria capture the complexity of doing internet governance? In addition, this paper also argues that the absence of specific and accurate language that defines pornography in the current law and the resulting virtual absence of enforceable legal sanctions on the ground is a result of the country's desire to break away from a past of censorship and control in favour of a legal outlook that values freedom of 
information and privacy rights over government intervention into media and business practices. The paper thus compares how two competing frameworks - the US and the European - are influencing Bulgaria's struggles over its pornography laws, both online and offline. Through a qualitative document analysis of the Bulgarian criminal and media law, the study engages in a systematic examination of the development of legal definitions of pornography, focusing on the most recent addition of language concerning online pornography, and how these definitions in turn reflect Bulgaria's struggle in defining its conceptual approach to media regulation in specific, and internet governance in general. Therefore, this study fills the void that Just \& Puppis (2012) described as the paucity of theoretically-grounded communication policy research.

\section{BRIEF CULTURAL HISTORY OF PORNOGRAPHY IN EASTERN EUROPE AND BULGARIA}

In Eastern Europe the most recent history of regulating pornography dates to the ideological shift triggered by the Soviet revolution. On the one hand, the socialist ideologies of the Soviet revolution advocated for openness in communicating and engaging in sexual relationships, celebrating a symbolic "victory" over the shackles of outdated moral codes. On the other hand, they also promoted a view of sexuality so clinical and driven by the ultimate goal of procreating to ensure the future economic survival of the regime, that it treated sex and, by extension any depictions of it, as animalistic, and ultimately, repulsive social practice (Borenstein, 2008). This ambiguous treatment of the topic of sex appeared a most convenient ideological narrative, which as Carleton (2005) pointed out, at the onset of the socialist revolution produced a liberating interpretation of sexual relationships and the laws that define them.

Stalin's ascent to power and the conservative values he espoused brought the possibility of a debate about sex and pornography to a screeching halt. Sexual discourse was in essence removed from the public conversation. The only allowed conversation about sex was focused on improving one's general sexual health, and occasionally, on improving a couple's sense of intimacy. "Adolescent sex education, called 'sanitary education' was reduced to instruction in hygiene and physiology" (Baban, 200o, p. 239), removing any and all visual allure of sexual seduction from sexual relationships.

Even though the official policy of the communist ideologues concerning sex was to treat it as taboo, it didn't deter the effort of local agents to introduce sexually provocative content - usually produced abroad and distributed through underground networks - in order to challenge existing norms and meet local demand. In countries such as Hungary, East Germany and Yugoslavia, which enjoyed a freer market and travel opportunities with access to the West, a more tolerant attitude towards Western produced commodities also translated into attitudes towards sex and pornography that strayed from the rigid ideological approach of the Stalinist era. The general approach in these countries was that content that is sexually provocative and in fact, pornographic, would be tolerated as long as it deters the socialist subjects from questioning the legitimacy of the political regime (Magó-Maghiar, 2009; Žikić, 2009).

The changing cultural climate of the 1980s, triggered by a growing exchange of contacts with Western content and cultural products alongside the steady decline of the economic success of the socialist state, lead to an increase in the circulation of pornographic materials. In Bulgaria, the distribution of smuggled pornography was already a thriving underground business; 
however, this "taboo" practice was a lot less invested with ideological intent. In fact, as Ibroscheva (2013) pointed out, "the socialist political establishment began to entertain the idea of more openness in its treatment of topics pertaining to the body-sex, erotica, and to some extent, even soft porn-only as an attempt to mitigate, if not entirely suppress, the growing discontent with the dismal economic output and stifling lack of political freedom" (p. 92-93). Gradually, homegrown publications that borrowed widely from erotic Western media, such as Playboy, Penthouse, etc, became sought after as the one Western import that provides instantaneous gratification and escape from reality. Goscilo (1996) noted in her extensive studies of the history of sex in post-Soviet Russia, "by the (sic) mid-1992 pornography was thriving as a mainstay of the novelties introduced along with kiwis and deodorants into Russia's capital” (p. 135).

While post-communist Russia was poised to experience a slow, yet widely profitable growth of the pornography market, in countries like Bulgaria and the former Yugoslav Republic of Serbia, the mushrooming of private television outlets also meant that widely sought after pornographic content was the perfect programming block filler, especially in the wee hours of the night. As Nikolic (2005) contended, "it was exactly media - which was in every other word closed - that 'opened the sexual views' of viewers" (p. 135). In East Germany, which found itself in the closest proximity to the West, the invasion of the West into the local post-socialist culture was most felt in what Norman (2000) called the "sex wave" that materialised in the production of erotic and pornographic films, a previously nonexistent cultural space. Daskalova (2000) also noted, a "real explosion" of the magazine publishing business took place, most notably demonstrated in the unprecedented and vastly popularised visuals of sex found in virtually every printed materials. As Deltcheva's (1996) pointed out, "the 'pornographic network' gained enormous dimensions - starting from the sales of Emanuelle at every street corner to the (pirated) Playboy photographs which periodically appeared in leading daily and weekly newspapers" (p. 307). However, the state remained conspicuously silent in making any attempts to define, regulate or sanction such content and its public displays.

\section{BULGARIA'S LEGAL ENVIRONMENT AND MEDIA POLICIES CONCERNING PORNOGRAPHY}

In Bulgaria, the legal language of communism dealt very strictly with all sexual "deviances" including masturbation, indecent public exposure, homosexuality and pornography, which was criminalised as soon as the communist regime was installed (Bulgarian Criminal Law, 1951; Special Section V, Crimes Against the Person: para. 9 Debauchery). As Popova (2010) contended, the purpose of the law was to define and uphold a sense of morality in which all types of erotic actions and sexual tools were condemned on the grounds of their antisocial and individualistic character, further amplified by the traditional rhetoric of disease and decay, in turn inspired by the socialist metaphor of the society as a living, breathing optimally performing organism. For example, masturbation was seen in this capacity as a medical condition with fatal consequences; homosexuality was perceived not only as a sexual but also as a social perversion, and as far as pornography was concerned, it was cast as the leading factor of moral decay and a highly successful weapon of Western ideological subversion. The Criminal Code (CC) introduced in 1968 and the standing law until recently, were defined as there to "defend the socialist rule of law and to educate citizens to respect the rules of the socialist community", and as such, prohibits the creation and dissemination of pornographic content and included a penalty of imprisonment of up to one year or a fine for doing so (Ognyanova, 2007b, para. 3). 
In the early years of the post-communist transition, pornography nestled itself as a "normalising" and virtually unsanctioned cultural mechanism, expressing a collective desire to join the market and exercise business entrepreneurship, while at the same time, filling a giant gap of "sexual education" left behind by the communist denial of sexual pleasure. Ninov (2001) reflected on this trend, stating that "freely speculating with its own ideas of democracy, the 'flesh market' is trying to defend its output, qualifying it as moral sexual education. The deficit in sexual literature and ignored sexual education before 1989, on the one hand, and the opportunity for free self-expression, for shedding inferiority complexes and doing away with censorship, on the other, are at the core of the unprecedented interest in pornographic publications" (p. 396).

To many experts, the unbridled access to pornographic content in Eastern Europe, and specifically Bulgaria, was seen as the unintended consequence of the maturation of a new market economy and the general liberalisation of the post-socialist transition. Similarly, a number of pundits also confidently predicted that porn "will be... channeled and confided to the needs of a group of people suffering from identity crisis or problem puberty..." (Ninov, 2001, p. 399), casting the sudden boom of previously tabooed media output as outgrowth of the transition. The fact remains that sexual content and to some extent pornography are now fully integrated in media practices and because, as Kirova (2012) pointed out, "for quite some people, their appearance is not a relict manifestation of outdated social relations, but rather an instance of 'innovation' and 'modernisation' of un-cool Bulgarian morality" (para. 36).

\section{MEDIA REGULATION, PORNOGRAPHY AND INTERNET GOVERNANCE: COMPLEX CHALLENGE}

While media moved fast to modernise, the government was extremely slow in responding to the need for policy and regulation. In fact its regulatory response was described as "overhasty, unpremeditated and premature" (Georgieva-Stankova, 2012, p. 195). After the collapse of the regime, the vacuum left behind by the control of the communist authorities now needed to be filled by media laws and policies that had no precedents in the cultural and legal communist past. In fact, as Ognyanova (2009) pointed out, "unlike other sectors of the economy, where the government adopts the so-called sectoral policies, no political acts (strategies) for the media sector in Bulgaria have been developed in the years of democratic transition” (p. 31).

The main media supervisory body called National Council for Radio and Television (NCRT) was established in 1997 and was renamed in 2001 to Council for Electronic Media (CEM). CEM is responsible for overseeing public service broadcasting, as well as commercial broadcasting, including advertising. Its members are chosen by the Parliament and the President. The current law guiding the operation of media in Bulgaria is the Radio and Television Act (RTA) of 1996, which took nearly six years to draft. To this day, however, the internet remains unregulated (Davidova, 2014).

Modernising Bulgaria's post-communist culture also meant acknowledging the fast-paced growth of technology and the infrastructure that enables its everyday use. Even though Bulgaria provided commercial internet services as early as 1992, access to those was not widely available and was often seen as a luxury. Today, Bulgaria boasts one the fastest internet connections in the world and 59 percent of population has access to some internet services (http://www.nsi.bg/en/node/6o9g). In addition, children are the most active internet users, 
with between 50 and 60 percent of those aged 7-19 currently using the internet (http://www.nsi.bg/ZActual_e/IT_HH20o6.htm). According to some non-governmental organisations, over 90 percent of children aged 8-16 have already seen online pornography (http://www.sva.bg). With data also pointing that the most frequently searched word in 2015 on the internet was "porn with Galena"1, it becomes clear that digital distribution networks enabled by the internet quickly caught up with making porn already part of the cultural mediascape in post-socialist Bulgaria.

The problem of defining pornography becomes complex enough to be described by Georgi Lozanov, the head of the CEM, as a "task worth the Nobel Prize" (bTV interview, aired 2 June 2015). Matters become even more complex when pornographic content is added to channels of dissemination and distribution, especially in light of the access to digital technologies and evoking debates about internet governance. "Internet governance" is a contested term with various definitions (Hofmann, 2005). As Mueller (2010) suggests, internet governance debates have often been reduced to an exaggerated dichotomy between the extremes of cyberlibertarianism and cyberconservativism. The former can resemble utopian technological determinism and the later is basically a state sovereignty model that extends traditional forms of state control to the internet with the goal of adequately serving the public interest.

In Bulgaria, the press and the internet are not currently regulated by CEM, despite multiple attempts to craft a press law and introduce internet-related regulations. As Marinova (2008) pointed out, "in principle the Bulgarian government does not regulate internet communications and is only responsible for the provision of services" (p. 3). However, a professional organisation handles the development and usage of the internet in Bulgaria. The Internet Society (Bulgaria), consists of two subgroups: Internet Architecture Board, dealing with architecture, protocols and standards, and Internet Engineering Steering Group, which is in charge of the technical processes in building the standards of internet performance. 2 Both organisations have been seen as defending the interests of the Bulgarian internet providers against excessive regulation and restrictive internet policies imposed by the state. Issues pertaining to the harmful content of pornography, specifically online child pornography, are monitored by non-governmental bodies such as the National Center for Safe Internet, while reported criminal activities concerning child porn are investigated by the Cybersecurity Department of the Ministry of Internal Affairs.

At present, there is no state regulatory authority in charge of overseeing and monitoring online services. CEM does not have the competency to license, and consequently monitor content distributed exclusively online. In fact, the current media regulatory framework doesn't even have a working definition of social media. With regard to television programmes that stream content online, this can be evaluated as an incomplete transposition of the Audiovisual Media Services Directive (AVMSD) and thus a violation of European law, which requires that each member state set up an independent regulator for AVMS that meet the criteria necessary to define user-generated videos and video sharing social media platforms. In the case of commercial communications via online channels, such activities are delegated to the purview of the NCRT, but the measures are not efficiently enforced yet. With regards to providing protection to minors, there is neither co-regulation nor self-regulation mechanism in place. The outcome of this lack of oversight is, as Ognyanova (2007a) points out, a misconstrued notion of protecting children and minors, which focuses on punishing internet pornography as crime, and not on preventing crime in the first place. "In the EU countries, the guiding principle of the law is to protect children, with fewer, but consistently enforced bans. In Bulgaria, all porn is banned, but children are given less protections under the law" (Ognyanova, 2007a, para. 5). This is indeed alarming as data from the National Center for Safe Internet shows that in 2015, there 
were over 2,500 hotline tips on sexual crimes against minors online, many of which were perpetrated by other minors (Lazarova, 2016, para. 1).

\section{BETWEEN THE EU AND THE US MODEL: RAMIFICATIONS FOR BULGARIA'S LAW}

Because Bulgaria joined the $\mathrm{EU}$ in 2007, its legal approach to media as well as other matters of judicial reform, is to be guided by directives set forth by the Council of the European Union. For example, media law enforced by the CEM is to be compliant with the guiding multilateral directive "Television Without Frontiers" (TWFD), which laid the universal principles and legal responsibilities surrounding the operations of media entities in the European Union member states (Council Directive 89/552/EEC, Art. 22 and 22a, 1989). With the exponential growth of the internet and the amount of pornographic content made available online, the directive was amended in 1997 after a meeting between the Council of the EU and representatives of the member states to address the regulation of harmful and illegal content on the internet, notably, child pornography (Art. 4 Council Recommendation, 98/560/CE, 1998 O.J. (L 270) 48, Annex 22.2 (a-c). Ultimately, the TWFD was expanded to also include pornographic material available on the internet, which bans among others, television programmes that could harm the physical, mental, or moral development of minors (Council Recommendation 98/560/CE, art. 4, 1997, O.J. (C70) 1). The EU has been engaged in an active pursuit to curb and eradicate child pornography on the internet by focusing on prevention, rather than criminal prosecution. As Eko (2009) argued, "The European Union emphasises measures-including content-based ones-in order to avoid the need to apply criminal prosecution and other enforcement measures that may be damaging to the right to personal communication, privacy and data protection as well as the right to disseminate nonprejudicial information" (p. 135).

The United States, on the other hand, has exhibited one of the most comprehensive sets of legal measures to deal with child pornography. The US approach is two-pronged. On the one hand, guided by the First Amendment, sexual expressions and pornography are treated as protected speech. The US Supreme Court has ruled that pornography is protected speech under the First Amendment and therefore, trying to ban it is unconstitutional. Because the internet regulatory regime in the United States is also defined by the concept of the "marketplace of ideas", the internet has been afforded the same protections as the press, which means that as far as pornography is transmitted or stored via internet means, it is protected by the First Amendment (Eko, 2009).

At the same time, case and statutory law have been applied and kept abreast of technological advancements to protect children and minors from the dangers of child pornography. Two notable examples include the Child Protection and Obscenity Enforcement Act (18 U.S.C. paras. 2251-2256 (1988) and the Child Pornography Prevention Act of 1996 (P.L. 104-208, Div A, Title I para. 101(a) [Title I, para. 121] 110). The Child Pornography Prevention Act of 1996 was part of the omnibus Communication Decency Act, which framed the internet as a dangerous space for children. As the internet became an increasing common site where both sexual predators stalked their victims and where pornographic content was freely available, Congress Acted by passing the Communication Decency Act of 1996 (CDA) as part of the Telecommunications Act of 1996, which to date is the primary legal document defining the functions of the internet (47 U.S.C. para. 223 et seq. (1996)). These attempts of the government to criminalise child pornography have been successfully challenged on multiple occasions but numerous entities, 
including the pornographic industries and civil liberties organisations, including the American Civil Liberty Union (ACLU), which eventually was followed by the passing of the Child Online Privacy Protection Act (COPPA) in 1998 (47 U.S.C. para. 231 (a)(1)). The constitutionality of COPPA was once again contested and eventually, the act was invalidated on the ground that filtering content and other technology-driven solutions are better than governmental intervention and criminalising content that might otherwise be afforded First Amendment protection (Eko, 2006). It becomes clear that European and US law differ significantly in the matter of treating online pornography and those differences are important to pinpoint in the case of Bulgaria's current struggles as it tries to reconcile competing legal frameworks that legislators seem to evoke in support of their proposed bills.

In Bulgaria, where as Marinova (2004, p. 4) points out, "the state regime has a largely laissezfaire attitude, and the field of communications is especially liberal," matters of streamlining legal definitions that do not violate the newly earned freedom of speech and yet, address problems with online and offline pornography adequately becomes challenging, to say the least. Realising the existence of two legal paths - the US one suggesting treating child pornography as crime while protecting porn in general, or the European approach, pursuing child porn as a human right violation, the Bulgarian Criminal Code was finally amended in 2007 to offer a new definition of "pornographic material":

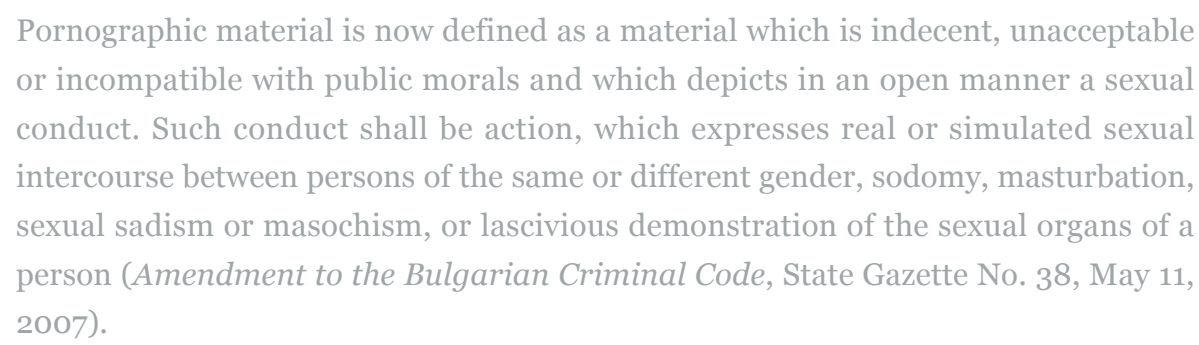

The provision of Article 159 of the same act was also amended to introduce for the first time legal sanctions directed towards online pornography. "A person who possesses or provides pornographic material for himself or for another person through a computer system or via other means, material that has featured a person who has not turned 18 years of age or one who has the appearance of such a person, shall be punished by imprisonment of up to one year or a fine of up to BGN 2,000" (ibid.). The sanctions, curiously, also differentiate the punishment for online and offline pornography, including prison time and a monetary fine, both of which were significantly higher for offline pornography compared to internet pornography, a measure possibly pointing to the fact that offline pornography involves a larger degree of intentionality and potential to inflict physical harm than online pornography.

\section{CONCLUSION}

There has been a general discussion as to whether the internet, as a general rule, lends itself to governance by traditional sovereigns or if something in the net's architecture resists such forms of control. In recent years, pornography has become a hot topic of discussion involving national and global governance. The speed, ease and accessibility of pornographic content today is indeed unprecedented and has proven virtually impossible to curb both in traditional and online settings. As York (2016, May 25) argued, " ...banning pornography is all but impossible, unless 
we're comfortable with the collateral damage". Bulgaria's standing challenge is to find a model language for its media law that addresses effectively pornographic content, borrowing from practices in the West, namely, the European Union and the United States. As a member of the $\mathrm{EU}$, Bulgaria is committed to its laws and directives, which define and guide the sanctioning and criminalising of child pornography, which is clearly demonstrated in the 2007 amended language of the Bulgarian Criminal Code. In its attempt to act as an "exemplary" member state of the EU, Bulgarian legislators proposed a blanket ban on all pornography, in order to protect "children and human dignity." On the other hand, Bulgaria is also shaking off the remains of communist censorship that stifled freedom of expression. In an attempt to emulate and adopt a new, US-inspired media philosophy that rejects government interference in the function of the press in any type and form, Bulgarian media embraced sexual content as a symbolic opposition to the morally contrived communist past. To satisfy, and perhaps please EU regulators beyond reproach, Bulgaria has effectively banned all porn, while at the same time, virtually failed to enact any of the sanctions it has mandated against transgressors. As Ognyanova (2007b) points out, "Bulgaria is a country of paradoxes - pornography is fully and completely banned, but you can find it nestled at the news kiosks, right next to school textbooks for sale" (par. 8).

Bulgaria's case also clearly demonstrates the vast cultural differences in how online pornography is defined and socially viewed and the wide range of law-enforcing capabilities and their desire to impose sanctions - demonstrating that imposing uniform legal rules is challenging, if not impossible. Since Bulgaria's media experts and legal advisors advocate that the pivotal role of such internet regulation is to protect children from the dangers of using digital technologies that could harm them, and because of the fact that other European countries have had favourable experience with co-and self-regulation instruments, the need for Bulgaria to introduce meaningful policies to monitor and sanction harmful use of new digital technologies directed towards children becomes even more pressing. Proposing legislature without defining what "media" or "pornography" actually mean is not different from what York (2016) calls a conflation of nudity, sexuality, and pornography, which seems more dangerous than pornography itself. Without transparency and a vibrant public debate that involves the participation of internet users, providers and regulators, trying to "ban" porn becomes a dangerous and potentially doomed exercise in defining the limits of free speech in the cultural environment of a transitional democracy that is still reconciling the past alongside the enormous market pressures of the present. In this sense, internet governance has significant public interest implications, diffusely distributed among new institutional forms, the private sector, and more traditional forms of governance and remains a critical factor in making long term policy changes that carry meaning, and not just gestures of symbolism. 


\section{REFERENCES}

Baban, A. (2000). Women's sexuality and reproductive behavior in post-Ceausescu Romani: A psychological Approach. In S. Gal \& G. Kligman (Eds.), Reproducing gender: Politics, publics and everyday life after socialism (pp. 225-257). Princeton, New Jersey: Princeton University Press.

Borenstein, E. (2008). Overkill: Sex and violence in contemporary Russian popular culture. Ithaca and London: Cornell University Press.

Burgelman, J. C. (1997). "Issues and assumptions in communications policy and research in Western Europe: A critical analysis." In J. Corner, P. Schlesinger and R. Silverston (Eds.), International Media Research: A Critical Survey (pp. 1-17). London and New York: Routledge.

Carleton, G. (2005). Sexual revolution in Bolshevik Russia. Pittsburgh, PA: University of Pittsburgh Press.

Child Pornography Prevention Act of 1996 (1996). (P.L. 104-208, Div A, Title I § 101(a) [Title I, § 121] 110).

Child Protection and Obscenity Enforcement Act of 1988 (1988). (18 U.S.C. §2257).

Children's Online Privacy Protection Act of 1998 (1998). 15 U.S.C. 6501-6505.

Council Recommendation 98/56o/CE, 1998 O.J. (L 270) 48 at art. 4, Annex 22.2 (a-c).

Daskalova, K. (2000). Women's problems, women's discourses in post-communist Bulgaria. In S. Gal \& G. Kligman (Eds). Reproducing gender: Politics, publics and everyday life after socialism (pp. 331-380.). Princeton, NJ: Princeton University Press.

Davidova, P. (2014, May 19). "How will the internet media be regulated in Bulgaria?" The Union of Bulgarian Journalists, available online http://sbj-bg.eu/index.php?t=22916.

Deltcheva, R. (1996). New tendencies in post-totalitarian Bulgaria: Mass culture and the media. Europe-Asia Studies, 48(2), 305-316.

Dworkin, A. [1979] (1999). Pornography: Men possessing women. The Women's Press: London.

Eko, L. (2009). Suffer the virtual little Children: The European Union, The United States, and international regulation of online child pornography, Journal of Media Law \& Ethics, 1(1/2), 107-149.

Engström, C. (2013, March 6). An EU proposal to ban porn through "self-regulation," available online https://christianengstrom.wordpress.com/2013/o3/o6/an-eu-proposal-to-ban-pornthrough-self-regulation/.

Hofmann, J. (2005). "Internet governance: A regulatory idea in flux," English translation available online

http://duplox.wzb.eu/people/jeanette/texte/Internet\%20Governance\%english\%20version.pdf.

Georgieva-Stankova, N. (2011)."Media regulations, ownership, control and the 'invisible' hand of the market”. Trakia Journal of Sciences, 9(30), 91-203. 
Goscilo, H. (1996). Dehexing sex: Russian womanhood during and after Glasnost. Ann Arbor, MI: University of Michigan.

Ibroscheva. E. (2013). Advertising, sex, and post-socialism: Women, media, and femininity in the Balkans. Lanham, MD: Rowman and Littlefield.

Just, N., \& Puppis, M. (2012). Trends in communication policy research: New theories, methods, and subjects. Chicago, IL: The University of Chicago Press.

Kendrick, W. [1987] (1996). The secret museum: Pornography in modern culture. University of California Press: Berkeley, Los Angeles and London.

Kipnis, L. (1996). Bound and gagged: Pornography and the politics of fantasy in America. Grove Press: New York.

Kirova, M. (2012, March 26). "Breeding inequality: Gender inequalities in Bulgarian advertising", Public Republic, available online at

http://www.public-republic.net/breeding-inequality-gender-identities-in-bulgarianadvertising.php.

Lazarova, U. (March 10, 2016). "More than 50 materials with child pornography and 20 internet pedophiles have been caught in 2015". Dnevnik.bg, available online

http://www.dnevnik.bg/bulgaria/2016/03/10/2719963_nad_50_materiala_s_detska_pornogr afiia_i_20_internet/.

Magó-Maghiar, A. (2009). Representations of sexuality in Hungarian popular culture of the 1980s. Medij. istraz. god. 16, br. 1, pp. 73-95.

Marinova, J. (2008). "National report for Bulgaria." In Hasebrink,U., Livingstone, S. and Haddon, L. (Eds.), Comparing children's online opportunities and risks across Europe: Crossnational comparisons for EU kids online. A report for the EC Safer Internet Plus Programme.

Mueller, M. (2010). Networks and states: The global politics of internet governance. Cambridge: MIT Press.

Nikolic, Tea (2005). Serbian sexual response: Gender and sexuality in Serbia during the 1990s. In A. Stulhofer \& T. Sanfort (Eds.), Sexuality and gender in post-communist Eastern Europe and Russia (pp. 95-125). New York: The Haworth Press.

Nikolova, E. (2011). Bulgaria. The media in South-East Europe: A comparative media law and policy study. Institute of European Media Law, available online

http://library.fes.de/pdf-files/bueros/sofia/o8097.pdf

Ninov, B. (2001). Forms of erotic expression. In N. Genov \& A. Krasteva (Eds.), Recent social trends in Bulgaria 1960-1995 (pp. 395-406). McGill, Montreal: Queen's University Press.

Norman, B. (2000). "Test the West": East German performance art takes on Western advertising. The Journal of Popular Culture, XXXIV: 255-267.

Ognyanova, N. (2007a, May 14). Pornography has been defined available online https://nellyo.wordpress.com/2007/05/14/pornography_definition/.

Ognyanova, N. (2007b, May 23). Online pornography makes an entry in Penal Code. Kapital, 
available online

http://www.capital.bg/biznes/tehnologii_i_nauka/2007/05/23/342834_onlain_pornografiiat a_gastrolira_v_nk/.

Ognyanova, N. (2009). Bulgarian media policy and law: How much Europeanization. Central European Journal of Communication, (02), 27-41.

Popova, M. (2004). "Regulating the internet: Between cyberanarchy and cybercensorship." LiterNet, 8: 57, avaialable online, http://liternet.bg/publish11/m_popova/regulation.htm. (in Bulgarian).

Popova, G. (2010). "Joyous austerity" in the representations of love and eroticism in socialist Bulgaria. Notabene, 15. Retrieved from http://notabene-bg.org/read.php?id=167.

Resolution of the Council and of the Representatives of the Governments of Member States, Meeting within the Council of 17 February 1997 on Illegal and Harmful Content on the Internet, 1997 O.J. (C 70) 1.

Telecommunications Act of 1996 (1996). Pub. L. No. 104-104, 110 Stat. 56.

Television Without Frontiers Directive (1989). Council Directive 89/552/EEC, 1989 O. J. (L. 298) 23 at arts. 22, 22a (as amended by Council Directive 97/36/EC, 1997 O. J. (L202) 60 at art. 22, 22a).

York, J. C. (2016, May 25). Who defines pornography? These days, it's Facebook. The Washington Post, available online https://www.washingtonpost.com/news/intheory/wp/2016/05/25/who-defines-pornography-these-days-its-facebook/.

Zankova, B. (2013). "Regulating media in the new media environment: Problems, risks and challenges based on five European countries' case studies." LiterNet, 8:159, available online, http://liternet.bg/publish28/bisera-zankova/reguliraneto.htm\#1a. (in Bulgarian).

Žikić, B. (2009). Dissidents liked pretty girls: Nudity, pornography and quality press in socialism. Medij. istraz. god. 16, br. 1, pp. 53-71.

\section{FOOTNOTES}

1. Galena is a famous Bulgarian pop-folk singer, known for sexually provocative music videos and rumored to have acted in amateur porn.

2. Bulgaria joined the Internet Society in 1997 and its Bulgarian chapter is headed by Veni Markovski, the owner of one of the largest internet providers in the country. 